\section{Ambient Assisted Living: Identifying New Challenges and Needs for Digital Technologies and Service Innovation}

\author{
Vivian Vimarlund', Elizabeth M. Borycki ${ }^{2}$, Andre W. Kushniruk ${ }^{3}$, Kerstin Avenberg ${ }^{4}$ \\ 1 Professor School of Engineering, Department of Computer and Information Science, Linköping \\ University, Sweden, Co-Chair WG Ambient Assisted Living \\ 2 Professor, School of Health Information Science, University of Victoria, Canada, Chair WG Ambient \\ Assisted living \\ 3 Professor and Director, School of Health Information Science, University of Victoria, Canada \\ ${ }^{4}$ On behalf of the Swedish interest organizations for Elderly, Stockholm, Sweden. Member of \\ SeniorNet and Active Seniors non-profit organizations
}

Such research is critical to the development of guidance for policy makers, suppliers and service providers.

Discussion: Older adults are asking for intelligent, assistive living solutions that help them to continue to live independent lives and remain socially included in their networks, associations, and communities. The elderly need services that stimulate and maintain their physical and intellectual capital. The development of innovative AAL environments is, however, a complex social process that involves the use and delivery of innovative ICT-based services. The implementation and use of AAL to support older adults involve service providers and elderly consumers. Conclusions: The results of the study may be of interest to policy makers, entrepreneurs, technology suppliers, service providers and health and social care organizations, who are willing to innovate and influence the development of the AAL market through their choices and decisions.

\section{Keywords}

Ambient assisted living, assistive technology, older adults, elderly, two-sided market, demand for services, challenges, user needs, business models

Yearb Med Inform 2021:141-9

http://dx.doi.org/10.1055/s-0041-1726492

\section{Introduction}

An Ambient Assisted Living (AAL) environment can be defined as "the use of information and communication technologies (ICT) in a person's daily life to enable them to stay active longer, remain socially connected, and live independently into old age" [1]. AAL includes the implementation and use of intelligent technology to enable the elderly to tackle the problems in the domain of assisted living and to live in their preferred environment longer [2].
Currently, the global AAL market is expected to reach up to 13.74 billion USD by 2027 [3]. Therefore, there has emerged a global interest in how older adults' (i.e., the elderly) use Internet and information and communication technology (ICT) in the home. With increased pressures arising from the need to deliver virtual services, while at the same time increasing social distancing between individuals (in response to the emergence of COVID-19), AAL technologies are being considered as a long-term solution to providing health and social care services during the current pandemic and into the future ${ }^{1}$.

In AAL and smart home environments, research, and development (R \& D) projects and business ventures often focus on the importance of technology as a way of improving quality of life and/or supporting individuals with cognitive impairments, with

\footnotetext{
The effective integration of health and social care services is expected to improve the care people receive. The term health care is usually related to the treatment, control or prevention of a disease, illness, injury or disability, and the care or aftercare of a person with these needs. The term social care focuses on providing assistance with activities of daily living, maintaining independence, social interaction, enabling the individual to play a fuller part in the society, protecting them in vulnerable situations, helping them to manage complex relationships and in some circumstances accessing a care home. Social care services can reduce the need for health care services because of the effects of the pandemic.
} 
the real-time delivery of digital services [4]. ICTs have the potential to improve health care while at the same time alleviating loneliness and social isolation among the elderly. Such health and social impacts are significant. They help to improve, expand, and sustain the older adults' social contacts, while at the same time improving the emotional well-being of the individual during the pandemic. Social and emotional contact are critical to psychological and physical health $[5,6]$.

Recently published studies (i.e., in 2020) have shown that among older adults, who were worried about the effects that COVID-19 was having on their lives, the main concerns of this population group focused on being unable to make plans, and to perform activities that affect their well-being. Staying in touch with family and friends remotely was noted by older adults as a way to avoid isolation and loneliness [7]. Wu (2020) suggested that social isolation and loneliness among older adults in the context of COVID-19 will be a global challenge [8]. Prior to the pandemic, most community-dwelling older adults actively participated in social activities, such as attending senior centers, church activities, traveling, and many other social events. However, due to the lockdowns imposed by governments in response to outbreaks of COVID-19, older adults can no longer undertake these activities. These restrictions have led to increasing levels of social isolation and feelings of loneliness among older adults as well as placing the elderly individual at risk of increased stress, anxiety, and depression [9]. There is a need to prevent the health effects of loneliness and social isolation on the elderly population. For governments and health care organizations, this has been a major focus of concern, due to the link between poor physical and mental health status. Low levels of physical activity led to increased blood pressure, heart disease, obesity, diminished immune system functioning, depression, anxiety, poorer cognitive functioning, an increased risk of Alzheimer's disease, and higher rates of mortality among the elderly [10-12].

In this study we aim to identify services that older adults would like to include in AAL living environments to diminish social isolation and loneliness in the time of the COVID-19 pandemic. In this research we also examine the challenges and needs of seniors who may use AAL using a needs approach. The results of the study may be of interest to decision makers, policy makers, entrepreneurs, as well as health and social care organizations, who are willing to influence and contribute to the further development of AAL. It is our hope consumers and stakeholders in the AAL living market will stimulate innovation through their choices and decisions regarding technologies they purchase.

\section{Background}

Digital technologies can improve socialization and they can facilitate older adults' ability to maintain an independent, healthy lifestyle in their homes. Many studies have suggested that older adults (i.e., individuals over the age of 65 years) do not use technology nor do they have the ability to learn how to use new technologies [13]. Older adults are generally considered "late adopters" of most technologies in these studies. In contrast, as a group the elderly have become increasingly more connected, as more Internet users age and become older adults. In Sweden, $96 \%$ of the population actively uses the Internet every day. Since 2010 the number of Internet users over the age of 75 has increased from $23 \%$ to $69 \%$, and the number of Internet users who are over the age of 66 represent 84 percent of Internet users [14]. In parallel, according to Canadian data, older adults represent one of the fastest growing segments of Internet users in country. Older adults are making substantive inroads into the digital world. As well, online activity among those aged 65 to 74 has risen 16 percent from 2013 to 2016. In the US, Internet adoption among the elderly has steadily increased over the past 15 years. Today, $67 \%$ of adults aged 65 and older state they go online and use ICTs daily [15]. Individuals who retired ten to fifteen years ago have become accustomed to the use of the Internet in their workplaces. Today, these individuals have reached the age of 76 or older and have taken those digital behaviors with them. The rapid spread of the use of the Internet, social media, technical devices, and platforms provides older adults with the opportunity to maintain an active and independent life while maintaining their contacts and networks, creating new conditions and development opportunities for the AAL market [4].

Research related to the everyday use of ICT among older adults has primarily focused on how the elderly make use of or understand digital technologies and applications in AAL living environments. Many of these studies have their origins in the medical and health sciences literature, where the elderly are seen as patients, or potential patients [16-18]. Very often these studies attempt to better understand how specific digital applications or devices can be made and used to improve health or social care service delivery, or to describe to what extent older adults use these digital services to communicate [19] and access other digital devices so they can receive services in their homes [20-22].

These studies often reveal that the elderly are less likely to have access to and use ICT in their daily activities. Therefore, these researchers have concluded that older adults stay out of the "information society". These studies have revealed important trends. Yet, the focus of these studies is often only on one side of the AAL market (i.e., the providers of the services or the users). Yet they do not offer information regarding the preferences of customers (i.e. older adults). In the next section of our paper, we outline the study methodology and findings.

\section{Method}

An explorative case study [23] was conducted with the aim to capture older adults' demands for ambient assisted living services in times of restrictions due to the effects of pandemics [24]. A case study methodology allowed us to examine this contemporary issue which is now of worldwide interest. Furthermore, the use of a case study methodology allowed us: (i) to perform the study in a real-life setting, (ii) capture experiences and expectations of older adults, and (iii) to deliver study outcomes that can lead to 
an in-depth understanding of the demands and expectations older adults have of AAL contexts. Moreover, case study research methods have allowed us to achieve an in-depth understanding of the phenomena, when there are no related or established theories to build on [23].

\subsection{The Context of the Study and the Survey}

The study participants were members of two non-profit senior organizations (i.e. older adults who had retired from work-life who live in Stockholm Sweden). Both organizations (i.e. SeniorNet and Aktiva Seniorer) have members and are located throughout Sweden. At the regional level there exists local associations that groups of individuals that have chosen to become members of the regional organizations because geographical proximity. The organizations, both at the national, and at the regional level, have the same goals, expectations, structure, internal and external relationship as well as resources.

The associations are politically, religiously and trade union independent. Members of both regional associations have similar interests. They organize, plan, and propose activities of interest to members and strive after to offer their members a network to avoid social distance and social isolation. They offered the same types of activities and programs, and they belong to the same "umbrella" or national, federative association. The organizations further have members with similar socio-economic backgrounds as well as similar life conditions and interests. The respondents of the study are consequently representative of both the organizations and the organizations' populations (i.e., membership population).

SeniorNet is a non-profit organization for old adults with needs and/or are interested in IT issues. SeniorNet offers data meetings and courses related to how to use and access to social media. Courses are arranged in collaboration with the adult national educational organization "Vuxenskolan" a study association that offers a broad range of courses and cultural program to people of all ages and backgrounds throughout Sweden.
Aktiva Seniorer, is a non-profit association that is politically and religiously independent of trade unions. The association aims to bring together retired adults, and to offer cultural and social activities. The organization provides individuals with the opportunity to avoid social isolation after retirement from working life. The association's activities take place in collaboration with the adult national educational organization "Medborgarskola", a study association that offers a broad range of courses and cultural programs, to people of all ages and backgrounds all over Sweden.

Both associations suspended all social activities in the middle of March as consequence of and extension of the COVID-19 pandemic. Both organizations followed the recommendations from the Public Health Agency, namely, to protect yourself and others (especially if you are a part of a highrisk group such as those 70 years of age and older), and to take personal responsibility to maintain social distance from others both indoors and outdoors.

\subsection{Phase 1: The Survey, Data Collection and Data Analysis}

Data were collected through a survey conducted at the end of March 2020. The survey took place over a three-week period. The survey questions were based on the concept of performance expectancy (i.e. the degree to which technology provides benefits to users in performing certain activities, namely social and cultural activities to remain included in the community), effort expectance (i.e. the use of the technology to remain connected and active), and social influence (i.e. the extent to which users perceive that important others as for instance family, friends, members of associations influence them), use technology to maintain their connection [25], as well as questions related to the challenges and expectations the respondents consider the AAL area have to adopted to actively access and use services. The survey was supplemented with questions regarding use of eHealth services (in which health and social care services are included) in times of pandemics. The survey also included demographic questions such as those specific to age, gender, educational level, and organizations the respondents were associated with.

Before the survey was sent to potential respondents, we randomly selected four individuals that represented the two organizations to assess the reliability of the questions. We asked them, in a one-hour interview, to comment on the questions and provide alternative questions that could be asked. All individuals commented on the need to see the AAL area as a more inclusive area, that includes healthy elderly that can manage their own life, live independently and be able to make their own decisions.

A letter was sent to introduce the objective of the survey, data collection method, a description of how data should be handled, the deadline to send the answers, information about privacy statements and confidentiality. We also asked about the respondents' willingness to participate in the validation process. The name of the project leader and the survey coordinator as well as their e-post and phone number were included in the introduction letter, in case some of the respondents wanted to contact them. The survey was designed to be completed in 30 minutes on average. To achieve this, we made a tradeoff between collecting detailed data for a specific, short time frame with collecting more general data about the respondents' expectations.

To collect the most information possible, we chose to develop a list of alternatives the respondents were asked to select from and prioritize. The questions also offered the possibility to add comments, reflections or to add complementary information and/or alternatives they considered of relevance after each block of questions in a free text box. None of the respondents added new questions or delivered complementary information.

\section{Data Collection}

The survey was distributed by e-mail to a total of $(\mathrm{n}=118)$ individuals associated with Senior.Net or Aktiva Seniorer. 58 individuals, active members of the SeniorNet, and 60 individuals, active members of Aktiva Seniorer received the survey. A total of 26 individuals from SeniorNet and 30 
individuals from Aktiva Seniorer answered the survey. Of these, 15 responses were recorded after sending a reminder e-mail a week after the deadline. Answers from a respondent, who could not open the form and send them via regular mail, as well as two answers that were coded as incomplete (i.e., less than half of the questions were answered) and were omitted in the presentation of the study results.

\section{Data Analysis}

Data were analyzed by the first author of this article in close collaboration with the survey coordinator. All answers were registered in tabular form. The number of respondents and the frequency of their answers for each question and respective sub-questions were recorded to facilitate an analysis of the results and to be able to list ICT services, as prioritized by the respondents.

Most of the respondents lived alone. There were in general, more women that were members of Active Seniors organizations than of the SeniorNet organizations. Most of the members of both associations had some academic degree (see Table 1).

Although there are different ways to classify the elderly population (i.e., following geriatric principles), we classify the respondents in the following groups: Youngest old (individuals between 65 and 70 years old), middle-old individuals between 70 to 75 years old, and Old old individuals between 75 and 80 years old. A few respondents were over 80 years old $(n=5)$ they built their own group.

The table above shows that most of the respondents belong to the group Old (75 to 80 years old). Most of the members of both associations had academic education. While SeniorNet seems to attract more male individuals, more women than men are members of Active Seniors.

\subsection{Survey Validation}

The results of the survey study were validated in two steps. In the first step the researchers sent the preliminary results by e-mail to the respondents who had written and expressed interest in reading and com-

Table 1 Age, level of education, and membership of the respondents

\begin{tabular}{|l|c|l|l|l|}
\hline & Senior Net $(\mathbf{n}=\mathbf{2 6})$ & \multicolumn{2}{l}{ Aktiva Seniorer $(\mathbf{n = 3 0})$} \\
\hline Male & 18 & 69 & 4 & 13 \\
\hline Female & 8 & 31 & 26 & 87 \\
\hline Age & & & & \\
\hline $\mathbf{6 5 - 7 0}$ & 6 & 23 & 3 & 10 \\
\hline $\mathbf{7 0 - 7 5}$ & 4 & 15 & 20 & 66 \\
\hline $\mathbf{7 5 - 8 0}$ & 14 & 53 & 3 & 10 \\
\hline $\mathbf{8 0}$ or older & 1 & 4 & 4 & 13 \\
\hline Education & & & & \\
\hline Vocational oriented & 2 & 7 & & \\
\hline High School & 4 & 15 & 3 & 10 \\
\hline University degree & 7 & 26 & 1 & 3 \\
\hline Academic degree & 13 & 50 & 25 & 83 \\
\hline
\end{tabular}

menting on the outputs of the survey. Three respondents immediately replied by e-mail indicating that the results were consistent with their survey responses as well as with our analysis and interpretation of the survey results. To ensure the accuracy of the outputs, we invited the respondents who expressed their interest in participating in the validation process and in commenting on the results of the survey $(\mathrm{n}=35)$ and participating in an interview.

The validation interview round was performed individually. Respondents were interviewed for one hour, outside their homes in parks or public areas. Recommendations to maintain social distance as recommended by the Public Health Agency were followed. During the interviews, the respondents were asked to verbally comment on the outcomes of the study. They were also asked to comment on the study results regarding the use or the non-use of health and social services such as Net.Doctors, virtual consultations, and/or the national e-health portal.

The manuscript was sent to our co-authors to identify (1) the level of literal replication (i.e. the conditions under which a particular phenomenon is likely to be found); (2) theoretical replication (i.e. the conditions when it is not likely to be found) of the outputs of the study; (3) discuss construct validity (i.e. if concepts being studied and operationalized are correctly); and (4) external validity (i.e. establish the domain to which a study's findings can be generalized).

\section{Results}

In this section of the paper the authors report on the results of the study. We list areas and types of services the respondents identified as being important and that need to be included in AAL environments of today. We also describe a series of challenges and needs that the AAL community and the market should consider when motivating older adults to use services (see Table 2).

\subsection{Areas and Type of Services}

All respondents stated that they had voluntarily quarantined and used digital technology to: (i) keep in touch or socialize with friends and family members; (ii) be able to continue to be active in their networks and associations; (iii) stay up to date and follow both national and international news, economic development and health-care information available from official portals (e.g., 1177 portals in Sweden) or published by healthcare authorities (iv) access to cultural performances; and (v) get involved in their own well-being through access to socio-cultural services that allow them to continue with their interests at distance.

It is interesting to note that health and social care services (for example, telemedicine or homecare) were not particularly demanded by this group of individuals. No respondent indicated that they applied, used, 
or were interested in receiving telemedicine services at home. Only a few respondents $(n=5)$ suggested the need to include interactive online doctors as a prioritized service. However, the respondents declared that they access and use the possibilities that My Care Contacts offer (the official healthcare platform in which individuals can get access to their EHR) to make appointments with general practitioners, renew medicines, and to access answers from COVID-19 tests and laboratory results. Participants in the validation process expressed the opinion that healthcare services in contrast to social care services are "in person services" and as such it is difficult to replace them totally by virtual services. This outcome becomes even more interesting if we consider all the initiatives that have been made worldwide to increase the use of eHealth services, and to stimulate the elderly population to take advantage of the opportunities that digitalization of services offers.

Awareness of security issues seems to be high among the respondents. They stated that: (i) it is difficult to know if the information they access is reliable; (ii) it is difficult to review sources; and (iii) there is a risk of being subjected to intrusion and misuse of information and opinions to a greater extent when accessing virtual services, especially if it is not possible to identify the legitimacy of the providers.

The results further show that the respondents asked for access to multi-home service alternatives (i.e. to access alternatives that are equivalent to each other) that guarantee quality, safety, and privacy. They also asked for networks that diminish risks and for the development of a trusted area where information can be transferred from producers to consumers in a structured, well-defined complete, easy, and undistorted manner. Further, the respondents indicated that AAL environments have to offer an area for interaction that guarantees and supports the following:

a) Knowledge around suppliers, services, devices, systems, or products;

b) Policies and rules producers and providers of services had to follow according to national social security regulations;

c) Business transparency where institutions are scrutinized to ensure that they behave appropriately; d) Information about producers or suppliers' participation in national or global marketplaces;

e) Warning systems that inform about brand or reputation of the producers and providers of services;

f) Recommender systems that select and recommend services adapted to their life situation;

g) Interactive platforms that enable interaction between the two sides of the market;

h) Rapid and easy access to services.

In Table 2, the areas, types of services and activities as well as challenges the areas that need to be addressed are described.

\subsection{Comments and Interpretation of the Results}

The results seem to indicate that it is necessary to capture expressed demand, to identify market challenges, to be able to understand how services should operate and serve older adults in practice as well as to develop guidance to policy makers and suppliers or providers of AAL services. Further, the results of the study seem to indicate that the area of AAL needs be studied from a multiple-sided market perspective (i.e., older adults, providers of health and social care services, developers of devices etc.).

We learned in this study that older adults ask for an assisted living context that helps them to continue to have an independent life and remain socially included in their networks, associations, and communities, primarily, as well as for services that stimulate and maintain their physical and intellectual activities.

\subsection{Needs and Challenges}

The development of AAL environments that include healthy and un-healthy older adults, is a challenge that involves innovative ICTbased services and that involves providers and consumers. Independent of the kind of service delivered, it seems that the area needs to approach complex changes that do not occur simultaneously. The complexity of the changes raises new challenges the
AAL community has to consider, such as described below.

\section{I - Developing of Control Mechanisms}

The AAL market, to which providers, suppliers, users, and stakeholders belong, needs to develop control mechanisms that exclude providers or suppliers in case the rules, guidelines and/or policies in the area are not followed to increase trust and confidence in the services and providers. Warning systems, networks of peers that evaluate the services as well as differences between the networks and organizations that can be accessed are also of importance for continued and systematic use of the services available. Furthermore, it is imperative to develop innovative business models that go beyond pure reimbursement or revenue models, and, to create a logical structure of how services can be delivered or accessed, distributed and/ or sell, depending on national rules, policies or social insurance systems.

\section{II - Customer Orientation as Key to Success}

In general, older adults search for services that allow them to maintain their habitus, i.e., lifestyle, and routines stable and more or less unchanged over time [26, 27]. Services that allow individuals to virtually "meet" and continue "to interact" with each other regularly are identified as important. Social activities services that allow one to keep patterns of conduct are considered as effective to maintain the social capital they have accumulated over their life $[28,29]$. Healthy older adults prioritize services that help them to reduce social isolation and loneliness, especially through services that help them to keep self-determination, autonomy, and to have fun and enjoy life even in pandemic situations.

Internationally, socializing is mentioned as being important for mental health and overall wellbeing. Connecting with family and friends, use of social media to stay connected, keeping hobby and cultural activities online, learning a new skill and protecting mental health are issues all governments recommend as being especially important for older adults during this challenging time of the COVID-19 pandemic [30]. 
Vimarlund et al.

Table 2 Areas, activities challenges, and needs

\begin{tabular}{|c|c|c|c|c|c|c|c|}
\hline $\begin{array}{l}\text { Areas and } \\
\text { type of } \\
\text { services }\end{array}$ & Activities & $\begin{array}{l}\text { Senior } \\
\text { Net } \\
\text { (n) }\end{array}$ & $\%$ & $\begin{array}{l}\text { Aktiva } \\
\text { Seniorer } \\
\text { (n) }\end{array}$ & $\%$ & $\begin{array}{l}\text { Challenges for the AAL } \\
\text { community }\end{array}$ & $\begin{array}{l}\text { Needs for the specific } \\
\text { areas }\end{array}$ \\
\hline $\begin{array}{l}\text { Social services } \\
\text { that allow } \\
\text { older adults to } \\
\text { keep social } \\
\text { interaction and } \\
\text { diminish } \\
\text { isolation }\end{array}$ & $\begin{array}{l}\text { Communicate with } \\
\text { friends } \\
\text { Keep in touch with } \\
\text { family members and } \\
\text { next of kind } \\
\text { Communicate with } \\
\text { multiple people more } \\
\text { often (more than once } \\
\text { a day) } \\
\text { E-commerce to order } \\
\text { foods and/or goods, } \\
\text { medicines, assistive } \\
\text { technology, etc. } \\
\text { Follow economic and } \\
\text { political developments } \\
\text { daily }\end{array}$ & 26 & $\begin{array}{l}100 \% \\
92 \% \\
88 \%\end{array}$ & 30 & $\begin{array}{l}100 \% \\
100 \% \\
70 \%\end{array}$ & $\begin{array}{l}\text { Provide innovative platforms } \\
\text { that enable producers and } \\
\text { consumers to benefit from } \\
\text { interacting with each other } \\
\text { when offering/demanding } \\
\text { and transferring services } \\
\text { Offer easy instructions about } \\
\text { how to rapid access the } \\
\text { services } \\
\text { List accredited suppliers }\end{array}$ & $\begin{array}{l}\text { Cooperation and mutual } \\
\text { understanding between } \\
\text { stakeholders, consumers, } \\
\text { and suppliers } \\
\text { Clear governance } \\
\text { Legal clarity } \\
\text { Innovative business models }\end{array}$ \\
\hline $\begin{array}{l}\text { Socio- cultural } \\
\text { and leisure } \\
\text { services to } \\
\text { keep older } \\
\text { adults social } \\
\text { active }\end{array}$ & $\begin{array}{l}\text { Theater, Movies and } \\
\text { Shows } \\
\text { Musicals and Opera } \\
\text { Concerts } \\
\text { Ballet } \\
\text { E-books } \\
\text { E-trips }\end{array}$ & 19 & $73 \%$ & 28 & $93 \%$ & $\begin{array}{l}\text { Accessibility to multi-home } \\
\text { alternatives } \\
\text { Network of peers that follow } \\
\text { up and evaluate services }\end{array}$ & $\begin{array}{l}\text { Data sets to support } \\
\text { interoperability } \\
\text { Certification or accreditation } \\
\text { criteria to analyze and } \\
\text { compare the level of } \\
\text { consistency of multi-home } \\
\text { services }\end{array}$ \\
\hline $\begin{array}{l}\text { Health and } \\
\text { social care } \\
\text { services } \\
\text { to facilitate } \\
\text { follow up or to } \\
\text { predict health } \\
\text { status } \\
\text { Reliable } \\
\text { services and } \\
\text { information } \\
\text { about diseases, } \\
\text { epidemics, } \\
\text { pandemics, etc. }\end{array}$ & $\begin{array}{l}\text { Contact } 1177 \text { Health } \\
\text { Portal or similar } \\
\text { applications } \\
\text { My health care } \\
\text { Pathway system } \\
\text { Health apps and } \\
\text { systems } \\
\text { Update information } \\
\text { published by official } \\
\text { authorities }\end{array}$ & 12 & $46 \%$ & 20 & $67 \%$ & $\begin{array}{l}\text { Warning systems and points } \\
\text { of contact in case something } \\
\text { goes wrong } \\
\text { Mechanisms that allow } \\
\text { exclusion of suppliers in } \\
\text { cases where the rules are } \\
\text { not followed } \\
\text { Official information about } \\
\text { the presence of several } \\
\text { providers and suppliers who } \\
\text { offer equivalent services } \\
\text { adapted to different life } \\
\text { situations }\end{array}$ & $\begin{array}{l}\text { Contracts that clearly state } \\
\text { the goals and objectives of } \\
\text { the relationship between a } \\
\text { vendor and a customer } \\
\text { Legal clarity, policies and } \\
\text { regulations adapted to the } \\
\text { ambient assisted living } \\
\text { market } \\
\text { Innovative business models }\end{array}$ \\
\hline $\begin{array}{l}\text { Secure and } \\
\text { safe services } \\
\text { that diminish } \\
\text { risks and fears }\end{array}$ & $\begin{array}{l}\text { Control that available } \\
\text { information is reliable } \\
\text { Reviewing sources } \\
\text { Avoiding others being } \\
\text { able to see } \\
\text { individual or personal } \\
\text { information } \\
\text { Avoiding contacts that } \\
\text { expose oneself to } \\
\text { intrusion and abuse of } \\
\text { data and opinions }\end{array}$ & $\begin{array}{l}10 \\
12\end{array}$ & $\begin{array}{l}38 \% \\
38 \% \\
46 \%\end{array}$ & $\begin{array}{l}22 \\
17\end{array}$ & $\begin{array}{l}90 \% \\
73 \% \\
56 \%\end{array}$ & $\begin{array}{l}\text { Networks or associations of } \\
\text { individuals that have the } \\
\text { same life situation to } \\
\text { stimulate social connectivity } \\
\text { Legal differences between } \\
\text { different kinds of } \\
\text { organizations }\end{array}$ & $\begin{array}{l}\text { Effective Contracts } \\
\text { Specific but reasonable } \\
\text { penalties } \\
\text { Vigilance and transparent } \\
\text { communication that } \\
\text { stimulates engagement }\end{array}$ \\
\hline
\end{tabular}




\section{III - Managing Digital Threats}

An interesting observation that emerges in this study is the trust in technology that the respondents have. There was no respondent who questioned the use of ICT as an enabling technology. However, there are issues regarding the quality, security and reliability of the information provided virtually. Although no comments were made regarding how these factors affect people's propensity to use ICT, it is important to keep in mind that accuracy, simplicity, quality, and security should be factors that affect the behavior and acceptance of ICT technologies, devices, and e-services in AAL environments.

The necessity to protect users and digital content providers against cyber-attacks, viruses and fraud has reached new levels with the global shift of economic activity online being further accelerated by the COVID-19 pandemic. Enabling older adults, providers, or suppliers of services to have trust in online environments is a crucial foundation for this shift. While the frequency of cyber-attacks varies among countries, the stakes attached to maintaining secure networks are increasing everywhere. This is especially the case in a time of crisis where older adults' ability to communicate online has become a necessity for maintaining and allowing them to remain active and independent.

\section{IV - Empowering Society}

The digital inclusion of older adults in AAL in the future should consider distinct paths of communication, different preferences regarding the type of services that are demanded in different life situations and differences in generational gaps that still exist in varying countries.

Worldwide policies for AAL appear to be in a state of constant reform. The immediate goal of many recent policy reforms has been to slow the growth of health spending by offering services individuals can manage by themselves or platforms that support the interaction between consumers and providers in order to move from physical to digital infrastructures. By increasing the use of digital services in AAL and by stimulating the growth of the market, a strong move to reducing public expenditure is envisaged. However, an important policy question is the extent to which approaches should be actively encouraged, and how such approaches should be organized to ensure sustainability and innovation.

\section{V - The Role of Entrepreneurial Collaboration}

Generic use of services available in AAL are influenced by the asymmetry of information that exists between the various stakeholders, and entrepreneurs active in the market. The area faces competition from firms and entrepreneurs that render services for customer groups or market segments. The respondents in this study pointed out an important issue that entrepreneurs should take into consideration. Namely the need to access to multi-home services through platforms that allow interaction between customers and suppliers. To match this challenge, it will be necessary to enable and stimulate entrepreneurial collaboration between the different actors joining an AAL market. Many entrepreneurs must take over the role as "switch tenders" in that they operate in a flexible yet-to some extent-projectable way. This ability, in turn, implies that actors belonging public organizations in the AAL market must radically change their organizational culture and behavior patterns from mainly being administration-oriented to more entrepreneurship-oriented institutions.

\section{Conclusions and Implications for the Area}

The AAL area is rapidly becoming fundamental for the delivery of health and social care services for older adults. Worldwide many different steps have been taken to increase the engagement of older adults, mainly focusing on the development of novel digital services that increase wellbeing or tackle some social challenges, such as the lack of qualified personnel or dwindling resources. At the same time, some effort is also spent for establishing a market in which both sides - consumers and providers - can interact and benefit from with each other [31]. Along these lines, there has been a great push to introduce "service innovation", "design thinking" and other tenants of the service-dominant logic [32] to open new collaborations between private and public actors [33].

Many questions remain to be answered, such as if the market will be reduced to services for patients with chronic diseases only or if it will be an inclusive area that offers services that aim to reduce social isolation and support social connectivity, even for the healthy elderly. To empower society as a whole demands a more holistic view of this area. This is not only to renew or remove regulations or to develop devices to monitor elderly at a distance. It is also about how to motivate individuals, in general, to change and adapt behavior to changing environments. The importance of customer orientation as an antecedent for service delivery success is supported by evidence from many research studies [34,35]. Even when value expectations of customers evolve over time [36,37]. The results of this study show that AAL environments needs to deliver services that bring value added to the elderly. Further, the results of the study also indicate the need to provide services that prevent social isolation and the feeling of loneliness among older adults, especially because of the risks for stress and depression [9] and their subsequent effects on physical and mental health [10-12].

In view of the importance of AAL environments, especially in times of a pandemic, we need to have a strategic role in accelerating the diffusion of services, in facilitating interaction, and in becoming more inclusive and offering services even for healthy older adults that search for services to maintain social interaction and diminish social isolation. It is not possible to predict the future, however, the results of this study suggest that older adults today search for information intensive services, network structures, rapid or immediate communication and opportunities to reach individuals regardless of geographical boundaries [38].

To give older adults the opportunity to "live normally" during voluntary quarantine, in times when their mobility is limited due to pandemic effects, seems to be an important factor for avoiding social isolation and loneliness. It is not known if this pandemic will change the interaction and communication patterns for a long time. 
However, a continued possibility is that the desire to access virtual services that allow for socializing and that support social-cultural and leisure activities will lead to greater demand to develop adequate societal, market and political support. In particular, this will be needed when formulating policies and regulations that support the innovativeness of the market and the renewal of the services. Even when adherence to isolation strategies should decrease over time, it is important to mitigate the effects and to avoid an increase in the morbidity of COVID-19 associated affective disorders.

Until today, eHealth national policies have mainly focused on how to develop and implement eHealth services as a complement or as substitute of healthcare services delivered in-situ, (at healthcare centers, hospitals, etc.) [29] and to discuss the incompleteness of the reforms carried out, or the need to re-organize healthcare organizations to become a dynamic and market-oriented sector. AAL, has however, not been mentioned as an explicit area in which cross-border collaboration is needed to develop a coherent and synchronized eHealth system

AAL must ensure the existence of a series of policies and actors that ensure security, safety, and regulation of virtual behavior. Even in the case where public supported AAL environments are developed, decisions from governmental authorities, policies and regulations or social and ethical issues are critical to address and must be developed using evidence-based approaches. It is therefore important to move from a stage of theoretical discussion to practical action and to emphasize the need to discuss the type of market AAL needs in order to develop sustainable services and environments. In particular, it is necessary to include AAL technologies, challenges, expectations, purposes and goals in every national eHealth policy to be able to innovate and renew the area.

The strength of the case study method used in this paper is that there is a possibility of capturing new insights in the AAL area. The data captured in this case study allowed us to better learn and understand expectations and demands from older adults in times of restriction such as during a pandemic. The knowledge sampled provides information and indications about, demands and challenges. The AAL-community needs to approach technology in a way that society can develop a sustainable area of technology use. In addition to this, the results of this study provide unique information regarding the need to link health and social care.

One limitation of this study is the fact that experimental reliability (i.e. the possibility to replicate the study in several countries in parallel) at the international level, cannot be demonstrated. It is possible that cultural and socio-political differences would influence the results of a replication study conducted in another country. However, despite this limitation, this study provides a good indication of the challenges and needs the AAL market needs to approach to create concrete advancements and innovate in the area. In future studies, it will be important to capture gender differences associated with expressed demands for AAL. In this study most of the respondents were female and therefore the case study methodology does not allow for generalization of the results. We have however delivered a framework that can be replicated and expanded upon in future studies.

\section{References}

1. AAL executive summary: Smarter implementation of digital solutions enhancing active and healthy living; 2019. Available from: www.aal-europe.eu.

2. Stephanidis $\mathrm{C}$, editor. Universal Access in $\mathrm{HCI}$ Ambient Intelligence in Assisted Living. Enable Elderly People to Handle Future interfaces, Part II, HCII, LNCS 4555. Berlin, Heidelberg: Springer-Verlag; 2007. p. 103-12.

3. Global Industry Size. In-Depth Qualitative Insights, Explosive Growth Opportunity, Regional Analysis by Market Reports World; Sept 2020. Available from: https://www.marketwatch.com/press-release/ambient-assisted-living-market-research-reports-2020-global-industry-size-in-depth-qualitative-insights-explosive-growth-opportunity-regional-analysis-bymarket-reports-world-2020-09-07

4. Vimarlund V, Wass S. Big Data, Smart Homes and Ambient Assisted Living. Yearb Med Inform 2014 Aug 15;9(1):143-9.

5. Tech-adoption climbs among older adults. Canada: PEW RESEARCH CENTER; 2016. Available from: https://www.pewresearch.org/ internet/2017/05/17/tech-adoption-climbs-amongolder-adults/

6. Caccioppo JT, Hawley LC. Perceived social isolation and cognition. Trends Cogn Sci
2009;13(10):447-54 .

7. Office for National Statistics. Coronavirus and the social impacts on older people in Great Britain. Indicators from the Opinions and Lifestyle Survey on the social impact of the coronavirus (COVID19) pandemic on older people in Great Britain. Office for National Statistics, April to May 2020. Available from: https://www.ons.gov.uk/peoplepopulationandcommunity/birthsdeathsandmarriages/ ageing/articles/coronavirusandthesocialimpactsonolderpeopleingreatbritain/3aprilto10may2020

8. Wu B. Social isolation and loneliness among older adults in the context of COVID-19: a global challenge. Glob Health Res Policy 2020;5;27. Available from: https://doi.org/10.1186/s41256-020-00154-3

9. Wu B, Petrovsky DV, Wang J, Xu H, Zhu Z, McConnell ES, et al. Dementia caregiver interventions in Chinese people: a systematic review. J Adv Nurs 2019;75(3):528-42.

10. DiNapoli EA, Wu B, Scogin F. Social isolation, and cognitive function in Appalachian older adults. Res Aging 2014;36(2):161-79.

11. Nicholson NR. A review of social isolation: an important but underassessed condition in older adults. J Prim Prev 2012;33(2-3):137-52.

12. Armitage R, Nellums L B. COVID 19 and the consequences of isolating the elderly. Lancet Public Health 2020 May;5(5):e256. Available from: https://doi.org/10.1016/S2468-2667(20)30061-X

13. Internetstiftelse. [Older people and the low-educated end up outside when community services go digital] Äldre och lågutbildade hamnar utanför när samhällstjänsterna blir digitala; 2019. Only in Swedish.

14. Internetstiftelse. [Digital exclusion] Digitalt utanförskap; Q1 2020. Only in Swedish.

15. Anderson M, Perrin A. Tech- adoption climbs among older adults. PEW RESEARCH CENTER; 2016. Available from: https://www.pewresearch. org/internet/2017/05/17/tech-adoption-climbsamong-older-adults/

16. Torp S, Hanson E, Hauge S, Ulstein I, Magnusson L. A pilot study of how information and communication technology may contribute to health promotion among elderly spousal careers in Norway. Health Soc Care Community 2008;16(1):75-85.

17. Harrefors C, Axelsson K, Sävenstedt D. Using assistive technology services at differing levels of care. J Adv Nurs 2010;66(7):1523-32.

18. Berner JS, Rennermark M, Jogréus C, Berglund J. Factors associated with change in internet usage of Swedish older adults (2004-2010). Health Informatics J 2013;19(2):152-62.

19. Choudrie J, Ghinea G, Songonuga VN. Silver surfers, e-government and the digital divide: An exploratory study of UK local authority websites and older citizens'. Interacting with Computers 2013;25(6):417-42.

20. Findahl O. [The Swedes and the Internet] Svenskarna och Internet 2013. Stockholm: Stiftelsen för Internetinfrastruktur; 2013. Only in Swedish.

21. Findahl O. [The Swedes and the Internet]Svenskarna och Internet 2014. Stockholm: Stiftelsen för Internetinfrastruktur, 2014. Only in Swedish.

22. Flöck M. Activity monitoring and automatic alarm generation in AAL-enabled homes. Chapter 2. 
Berlin: Logos Verlag Berlin GmbH; 2010.

23. Yin RK. Case study research: Design and methods. Los Angeles, CA: Sage; 2014.

24. Venkatesh V, Thong J, Xu X. MIS Q 2012;36(1):157-78.

25. Caccioppo JT, Hawley LC. Perceived social isolation and cognition. Trends Cogn Sci 2009;13(10):447-54.

26. Shankar A, McMunn A, Banks J, Steptoe A. Loneliness, social isolation, and behavioral and biological health indicators in older adults. Health Psychol 2011;30(4):377.

27. Dumais S. Cultural Capital, Gender, and School Success: The Role of Habitus. Sociology of Education 2002;75(1):44-68.

28. Dumais S. Cultural Capital and First-Generation College Success. Poetics 2009;38(3):245-65.

29. Government of Canada. https://www.ottawapublichealth.ca/en/public-health-topics/Older_Adults_ and_COVID-19.aspx

30. Au N, Ngai EWT, Cheng TCE. A critical review of end-user information system satisfaction research and a new research framework. Omega 2002;30(6):451-78.

31. Vargo SL, Lusch RE. Service-dominant logic: Continuing the evolution. J Acad Mark Sci 2008;36(1):1-10.

32. Vimarlund $\mathrm{V}$, editor. The future of Two-sided eHealth markets (chapter 11). In: e Health two-sided markets: Implementation and Business Models. Elsevier; 2017.

33. Shankar A, McMunn A, Banks J, Steptoe A. Loneliness, social isolation, and behavioral and biological health indicators in older adults. Health Psychol 2011;30(4):377-85.

34. Nevo S, Wade M. The Formation and Value of IT-Enabled Resources: Antecedents and Consequences of Synergistic Relationship. MIS Quarterly 2010;34(1):163-83.

35. Sprenger C. An Endowment Effect for Risk: Experimental Tests of Stochastic Reference Points. Journal of Political Economy 2015;123 (6):1456-99.
36. Andreoni J, Kuhn MA, List JA, Samek A, Sokal $\mathrm{K}$, Sprenger C. Toward an understanding of the development of time preferences: Evidence from field experiment, J Public Econ 2019;177:104039.

37. Connell NAD, Young TP. Evaluating healthcare information systems through an enterprise perspective. Inf Manag 2007;44(4):433-40.

38. Vargo SL, Lusch RE. Service-dominant logic: Continuing the evolution. J Acad Mark Sci 2008;36(1):1-10.

Correspondence to:

Vivian Vimarlund

Professor in Informatics and Health Informatics

Department of Information and Computer Science (IDA)

Linköping University, Sweden

E-mail:Vivian.Vimarlund@liu.se 